\title{
Double crisscross sternal wiring and chest wound infections: A prospective randomized study
}

Tomaso Bottio, MD

Giulio Rizzoli, MD

Vladimiro Vida, MD

Dino Casarotto, MD

Gino Gerosa, MD
From the Department of Cardiovascular Surgery, University of Padua Medical School, Padua, Italy.

Received for publication April 8, 2003; revisions requested May 12, 2003; revisions received May 27, 2003; accepted for publication June 9, 2003.

Address for reprints: Tomaso Bottio, MD, Istituto di Cardiochirurgia, Università di Padova, Via Giustiniani 2, Padova, Italy (E-mail: tomaso.bottio@unipd.it).

J Thorac Cardiovasc Surg 2003;126:1352-6

Copyright $\odot 2003$ by The American Association for Thoracic Surgery

$0022-5223 / 2003 \$ 30.00+0$

doi:10.1016/S0022-5223(03)00945-0
Objective: We sought to assess the efficiency of 2 different sternal wiring techniques in preventing deep sternal wound infection or sternal instability.

Methods: Seven hundred patients were randomized to 2 different groups according to chest-closure techniques. Three hundred fifty patients who underwent a peristernal double crisscross wire closure were included in group X, whereas 350 patients who underwent a standard transsternal closure were included in group T. After sternal closure, the technique for wound suturing was the same for both groups, namely triple-layer sutures up to the intracutaneous skin. All data were prospectively collected and entered in our institute database.

Results: The 2 groups of patients were comparable for sex, age, preoperative risk factors, and operative procedures. The overall mortality rate was $4.3 \%$ in group $\mathrm{X}$ and $4.6 \%$ in group T. Postoperative morbidity and mortality were comparable between the 2 groups, unlike for sternal wound complications. None of the patients included in group $\mathrm{X}$ had superficial or deep wound complications, whereas in group T 7 (2\%) patients presented with a superficial sternal wound infection, $6(1.7 \%)$ presented with a deep chest wound infection with sternal instability requiring re-exploration $(P<.05)$, and 3 presented with a sternal instability caused by sternum disruption without infection. Among patients with deep wound infection and sternal instability, 1 patient died, resulting in a mortality rate of $16.7 \%$.

Conclusions: The peristernal double crisscross wiring technique achieved a greater sternal stability, resulting in a lower incidence of wound infection in association with triple-layer closure of suprasternal tissues.

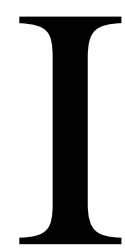

$\mathrm{n}$ cardiac surgery sternal wound instability, infection, or both are infrequent but life-threatening complications ${ }^{1,2}$ leading to a variable mortality rate ranging from $14 \%$ to $47 \% .^{3}$ The pathogenesis is not yet clearly defined, and many authors have identified several factors, either patient or surgeon related, as potential causes. ${ }^{4}$ However, Kirklin and Barratt-Boyes ${ }^{5}$ reported that sternal instability and wound infection are concomitantly present in the majority of cases. In the belief that deep wound infection occurrence might be a consequence of technical pitfalls, prevention of sternal instability caused by suboptimal sternal wiring techniques might grossly reduce the incidence of such complication.

To compare the effect of different sternal wiring techniques on sternal infection, we randomly assigned 700 consecutive patients to either double crisscross sternal wiring or single transsternal wiring closure. Patients were prospectively followed up, and data were entered in the database of the Cardiac Surgery Department of Padua University. 


\section{Material and Methods}

Between January 1999 and December 2002, a total of 2451 consecutive adult patients underwent cardiac operations through a median sternotomy at the Department of Cardiovascular Surgery of Padua University.

In the same time frame, 700 patients were randomly assigned, according to sternal closure technique, to 2 groups: standard transsternal and peristernal crisscross double-wire techniques. After the chest closure, the policy for wound suturing was the same for both groups, namely triple-layer sutures up to the intracutaneous skin. The incidence of sternal wound complications was assessed during the entire follow-up period.

\section{Patient Preparation and Surgical Technique}

In our protocol preoperative skin preparation consists of 2 showers with $4 \%$ clorhexidine the evening and morning before the operation. Between the 2 showers, the patient undergoes electric hair removal. In the operating room the skin is disinfected with polyvinylpyrrolidone (iodine solution). Patients receive antibiotic prophylaxis with vancomycin $(15 \mathrm{mg} / \mathrm{kg}) 1$ hour before the start of anesthesia. Intravenous antibiotic prophylaxis is then completed with cefazolin $(30 \mathrm{mg} / \mathrm{kg})$. A median sternotomy was used in all patients included in the study group. For patients operated on during cardiopulmonary bypass, moderate hypothermia and aortic crossclamping were used. Cardioplegic arrest was achieved with antegrade and retrograde cold blood cardioplegia infusion repeated at 20-minute intervals, with additional topical cooling. The use of diathermy and bone wax was similar during hemostasis phases.

Our policy for chest wound closure after sternal wiring is to use a triple-layer technique up to the intracutaneous skin closure. From deep up to the surface, the presternal fascia is closed with 1-0 Vicryl (Ethicon) sutures, the subcutaneous tissue with 0-Vicryl sutures, and the skin with 3-0 Vicryl sutures. The 3 sutures, performed in continuous stitches, are resorbable.

Postoperative antibiotic prophylaxis consists of administration of vancomycin $(7 \mathrm{mg} / \mathrm{kg}$ ) every 8 hours for 48 hours and cefazolin $(14 \mathrm{mg} / \mathrm{kg})$ every 8 hours until the central venous catheter and chest drains were removed.

In our practice, in the postoperative period the targeted glucose value should be less than $150 \mathrm{mg} / \mathrm{dL}$. The control value is obtained in the first postoperative period by means of intravenous infusion of rapid-acting insulin.

The 700 patients were randomly assigned to either the double crisscross sternal wiring technique or the standard transsternal wiring closure. Three hundred fifty patients (group X) were assigned to the peristernal double crisscross wiring technique (Figure $1){ }^{6}$ whereas the other 350 patients (group T) underwent transsternal wiring closure. In the presence of uncontrolled diabetes, chronic obstructive pulmonary disease, takedown of both internal thoracic arteries, paramedian sternotomy, or very frail sternal bone, osteoporosis, or both, before reapproximating the sternum, a bilateral parasternal steel wire was used to laterally support the sternum. Preference was given to the technique of Robicsek and colleagues, ${ }^{7}$ when a standard closure was used, or to the technique of Sutherland and associates (Figure 1), ${ }^{8}$ when a peristernal crisscross double-wire suture was accomplished.

\section{Data Collection and Statistical Analysis}

All preoperative, intraoperative, and postoperative data were prospectively collected and entered in the database (Table 1). Previously published guidelines ${ }^{4}$ for reporting sternal wound infections were used to standardize definitions.

The prevalence of risk factors and the cumulative incidence of perioperative and in-hospital sternal wound complications for the 2 groups were compared with the Fisher exact test for categoric variables and the $t$ test for continuous variables.

Results are reported as the mean \pm SD in the text and tables.

\section{Results}

The 700 patients were comparable according to sex, age, and operative procedure (Table 1). Preoperative risk factors were not significantly different between the 2 groups, whereas postoperative complications differed significantly only for sternal wound complications (Table 2).

In group $\mathrm{X}$ no patients experienced either a superficial or a deep wound complication, whereas in group T $7(2 \%)$ patients presented with a superficial sternal wound infection, and $6(1.7 \%)$ patients presented with a deep chest wound infection with sternal instability requiring re-exploration. The causative microorganisms were in the majority of cases gram-positive bacteria: Staphylococcus aureus or Staphylococcus epidermidis in 8 patients and Escherichia coli in 1 patient. In the remaining 4 patients the microorganisms were gram negative: Enterobacter cloacae, Pseudomonas aeruginosa, and Serratia marcescens. Three more patients in group $\mathrm{T}$ underwent re-exploration because of sternal instability without infection, whereas no cases of sternal disruption were observed in group $\mathrm{X}$. In those cases either with or without infection, the cause of sternal instability has been recognized in sternum disruption without any evidence of broken wires. Two $(0.6 \%)$ patients of group $\mathrm{X}$ and $3(0.8 \%)$ patients of group $\mathrm{T}$ experienced a wound infection at the site of the saphenous vein harvesting $(P=$ not significant). Clinical data for these patients are reported in Table 3. In both groups when a bilateral parasternal wire suture was added in the presence of an osteoporotic sternum, no signs of either superficial or deep wound infection were evident. Parasternal wire suturing was performed in $10 \%$ of group $\mathrm{X}$ patients and $9 \%$ of group $\mathrm{T}$ patients. The overall mortality rate was $4.3 \%$ in group $X$ and $4.6 \%$ in group $\mathrm{T}$. The causes of death were as follow: brain damage ( 6 in group $\mathrm{X}$ and 5 in group $\mathrm{T}$ ), low-output syndrome caused by acute myocardial infarction ( 8 in group $X$ and 9 in group $\mathrm{T})$, respiratory failure with prolonged ventilatory assistance ( 1 in group $\mathrm{X}$ and 1 in group $\mathrm{T}$ ), and deep chest wound infection with sternal instability ( 1 in group $\mathrm{T}$ ). Among patients who had a deep wound infection with sternal instability, 1 patient died, resulting in a mortality rate of $16.7 \%$. 

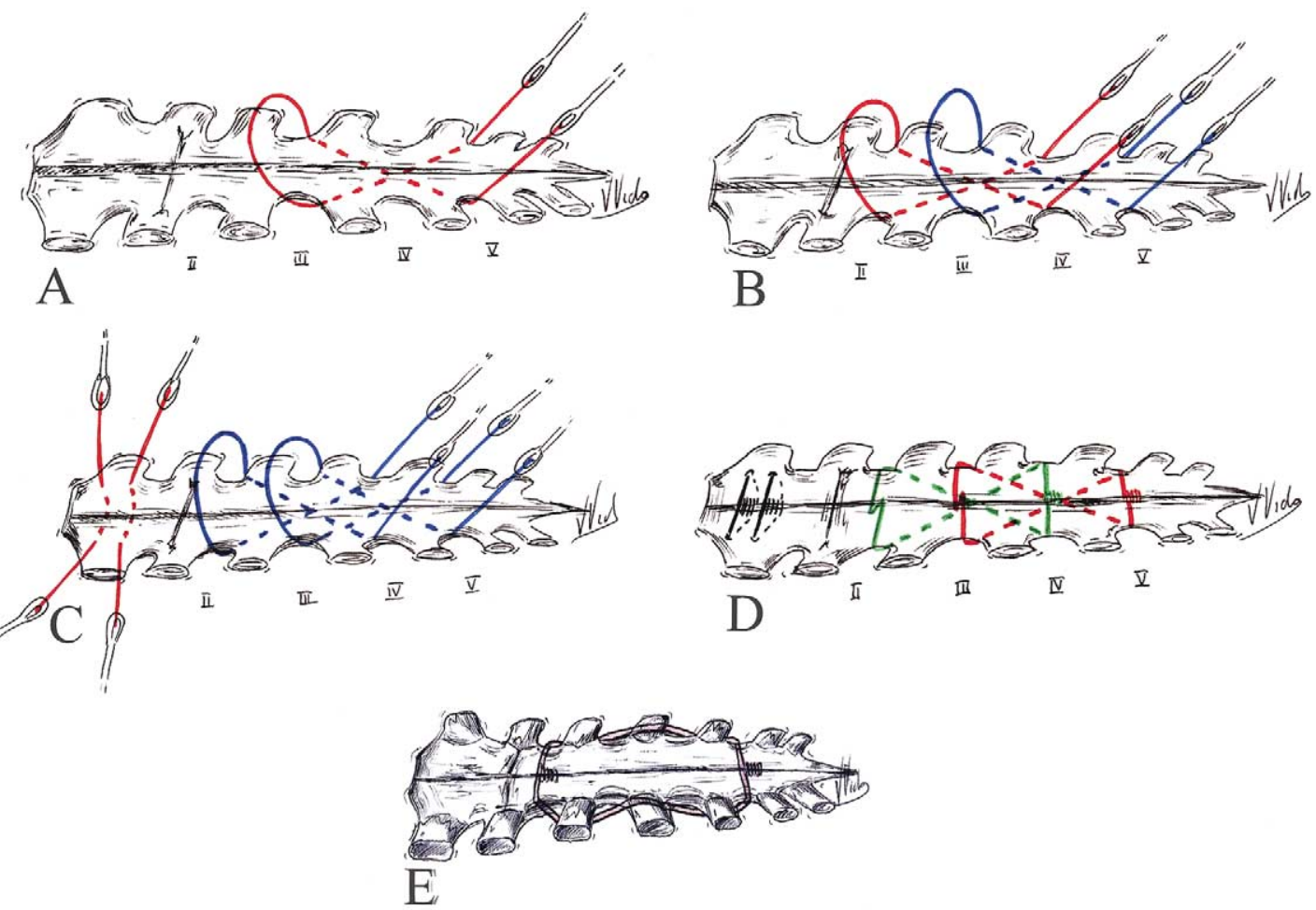

Figure 1. The sternum is caged by wire sutures in a crisscross fashion that exert force from top to bottom on one side and in the opposite direction on the other sternal side. A, The first wire penetrates through the fifth intercostal space running to the contralateral third and then from the opposite third to the contralateral fifth. B, The second wire penetrates through the fourth intercostal space running to the contralateral second and then from the opposite second to the contralateral fourth. C, The last 2 wires fix the sternum in a standard fashion. D, The sternum as it appears at the end of the procedure. A Z twist is accomplished within double crisscross wires to complete equilibration and distribution of forces. $E$, In the presence of frail sternal bone or sternal dehiscence, a 1-way bilateral parasternal wire suture prepared according to the Sutherland technique is added to reinforce the closure, avoiding the direct devastating action on the bone by sternal wires. Solid lines depict suprasternal wire tracts, and dotted lines depict deep sternal wire tracts. The red wire is the running wire, and the blue wire is already set.

TABLE 1. Operative procedures

\begin{tabular}{|c|c|c|c|}
\hline & Group X (350 patients) & Group T (350 patients) & $P$ value \\
\hline \multirow{4}{*}{$\begin{array}{l}\text { Sex (male/female) } \\
\text { Age (y) } \\
\text { CABG on pump }\end{array}$} & $245 / 105$ & $241 / 109$ & NS \\
\hline & $66 \pm 10$ & $65.6 \pm 9.6$ & NS \\
\hline & Single ITA, $95 \%$ & Single ITA, $95.3 \%$ & NS \\
\hline & Double ITA, 5\% & Double ITA, $4.7 \%$ & NS \\
\hline \multirow[t]{2}{*}{ ОРСАВ } & Single ITA, $98 \%$ & Single ITA, $97.8 \%$ & NS \\
\hline & patients $\quad$ Double ITA, $2 \%$ & Double ITA, 2.2\% & NS \\
\hline Valve replacement-repair & $81(23 \%)$ Patients & $80(23 \%)$ patients & NS \\
\hline Mixed lesions & $47(13 \%)$ Patients & $48(13.6 \%)$ patients & NS \\
\hline
\end{tabular}

CABG, Coronary artery bypass grafting; ITA, internal thoracic artery; OPCAB, off-pump coronary artery bypass. NS, Not significant.

\section{Discussion}

Sternal wound complications, in addition to the associated risks of morbidity and mortality, determine a 3 times increment of hospitalization costs as a result of prolonged inhospital stay, complicated assistance, and frequent intensive care unit readmissions. ${ }^{9}$
This prospective and randomized study analyzes our experience with 2 different sternal wiring techniques in preventing sternal instability and wound infection: standard transsternal versus peristernal double crisscross wiring.

Several strategies to prevent mediastinitis, sternal dehiscence, or both have been previously published..$^{3,4,10-13}$ Ro- 
TABLE 2. Preoperative risk factors and post operative complication rates according to sternal wiring technique

\begin{tabular}{|c|c|c|c|c|}
\hline & & Group X & Group T & $P$ value \\
\hline \multirow[t]{11}{*}{ Preoperative risk factors } & Redo surgery & $6.7 \%$ & $6.5 \%$ & NS \\
\hline & Emergency surgery & $5.5 \%$ & $6 \%$ & NS \\
\hline & Myocardial infarction & $24 \%$ & $25 \%$ & NS \\
\hline & Ejection fraction $<30 \%$ & $7.4 \%$ & $7.2 \%$ & NS \\
\hline & Pulmonary hypertension & $7.8 \%$ & $7.4 \%$ & NS \\
\hline & COPD & $27 \%$ & $28 \%$ & NS \\
\hline & Renal failure & $22 \%$ & $20 \%$ & NS \\
\hline & Peripheral vascular disease & $9 \%$ & $10 \%$ & NS \\
\hline & Neurocerebral events & $14 \%$ & $12.9 \%$ & NS \\
\hline & Diabetes & $19 \%$ & $18.5 \%$ & NS \\
\hline & Previous surgery IABP & $1 \%$ & $1.2 \%$ & NS \\
\hline \multirow[t]{12}{*}{ Postoperative complications } & Myocardial infarction & $7 \%$ & $7 \%$ & NS \\
\hline & IABP insertion & $5.7 \%$ & $6 \%$ & NS \\
\hline & Renal failure & $18 \%$ & $18.6 \%$ & NS \\
\hline & Neurocerebral events & $3.7 \%$ & $4 \%$ & NS \\
\hline & Re-exploration for bleeding & $5.4 \%$ & $5.2 \%$ & NS \\
\hline & Prolonged respiratory assistance & $10 \%$ & $10.3 \%$ & NS \\
\hline & Atrial fibrillation & $31 \%$ & $30.5 \%$ & NS \\
\hline & Superficial wound infection & $0 \%$ & $2 \%$ & $<.05$ \\
\hline & Deep wound infection & $0 \%$ & $1.7 \%$ & $<.05$ \\
\hline & Infection, nonsternal wound related & $4 \%$ & $3.7 \%$ & NS \\
\hline & Length of ICU stay (d) & $3.4 \pm 8$ & $3.7 \pm 10$ & NS \\
\hline & Mortality & $4.3 \%$ & $4.6 \%$ & NS \\
\hline
\end{tabular}

$N S$, Not significant; $C O P D$, chronic obstructive pulmonary disease; $I A B P$, intra-aortic balloon pump; ICU, intensive care unit.

bicsek and colleagues ${ }^{7}$ proposed a parasternal wire suture in the presence of a frail and osteoporotic sternum or when a sternal dehiscence has already occurred. Sutherland and associates ${ }^{8}$ modified and simplified this sternal supporting technique. Different conditions, including diabetes, obesity, double internal thoracic artery takedown, chronic obstructive pulmonary disease, prolonged operative time, and need for repeated blood transfusion have been identified as potential risk factors. The entire armamentarium of therapeutic options for the effective treatment ranges from simple prolonged antibiotic prophylaxis to complete sternectomy and wound debridement with complex reconstructive procedures. ${ }^{4,13}$ Nevertheless, prospective and randomized studies focusing on sternal wound complication treatment or prevention are rare. Recently, Risnes and coworkers ${ }^{14}$ prospectively compared 300 patients undergoing coronary artery bypass grafting (either valve or combined procedures) who were randomly assigned after sternal closure to intracutaneous or transcutaneous suture techniques. According to their experience, the transcutaneous technique guarantees better results, with a 3\% incidence of infection compared with $8 \%$ in patients sutured with the intracutaneous technique. Hirose and Takahashi, ${ }^{15}$ however, rebutted these conclusions, highlighting how crucial it is to reduce the presternal dead space between the skin and the underlying tissue to prevent the onset of wound infection. They achieved such results using a triple-layer closure technique up to the skin. In their experience the subsequent intracutaneous contin-
TABLE 3. Deep sternal wound infections (6 patients) and operative risk factors

\begin{tabular}{llc}
\hline & & $\begin{array}{c}\text { No. of } \\
\text { patients }\end{array}$ \\
\hline Risk factors & $\begin{array}{l}\text { Diabetes } \\
\text { Chronic obstructive }\end{array}$ & 2 \\
& $\begin{array}{l}\text { pulmonary disease } \\
\text { Operative risk factors }\end{array}$ & 2 \\
& Chronic renal failure & 3 \\
& Single ITA & 2 \\
& Double ITA & 1 \\
& $\begin{array}{l}\text { Prolonged ventilation } \\
\text { Re-exploration for bleeding } \\
\text { With acute myocardial }\end{array}$ & 3 \\
& infarction & 1
\end{tabular}

ITA, Internal thoracic artery.

uous stitches were well comparable with percutaneous stitches in terms of infection rates, while being cosmetically superior.

On the basis of the observation that in the vast majority of cases of sternal wound infection some degree of sternal instability is always present, ${ }^{5}$ we randomized patients to 2 different sternal wiring techniques using the same triplelayer suture for fascia, subcutaneous tissue, and skin. The overall results, in terms of superficial and deep wound infection incidence, obtained with the standard wiring technique are comparable with those reported in the literature. $^{3,14,15}$ These excellent results support the effort we make to provide continuous and scrupulous patient care. On 
the other hand, the outcome obtained in patients undergoing closure by means of the peristernal double crisscross wiring technique was by far superior. None of those patients experienced a superficial or deep wound complication. Therefore we think that superior stability is granted by the opposite and oblique forces exerted on the caged sternum through the double crisscross wiring technique, reducing the sternal microcrunch and, consequently, the presternal tissue shifting. This greater stability allows superior results and accomplishes a real prophylactic strategy. Additional evidence of the importance of sternum stability over infection comes from the results we obtained with parasternal reinforcement in the subgroups of high-risk patients. When dealing with these patients, to reduce the presternal dead space, we preferred to adopt the simplified Sutherland procedure as opposed to the Robicsek technique in group $\mathrm{X}$ because the latter restrains the perfect apposition of the presternal fascia. As a matter of fact, in such cases, regardless of the sternal wiring technique adopted, no signs of superficial and deep wound infections were evident. Therefore we did not observe any difference between the 2 reinforcement techniques in terms of efficacy.

Sternal stability associated with triple-layer closure of suprasternal tissues, especially in high-risk patients living in disadvantageous geographic areas, appears to be the most important determinant to reduce sternal wound infection, and the peristernal double crisscross wiring technique is by far superior to the standard transsternal technique in achieving this goal.

\section{References}

1. Loop FD, Lytle BW, Cosgrove DM, et al. Sternal wound complications after isolated coronary artery by-pass grafting: early and late mortality, morbidity and cost of care. Ann Surg. 1990;49:179-87.

2. Molina E. Primary closure for infected dehiscence of the sternum. Ann Thorac Surg. 1993;55:459-63.

3. Stahle E, Tammelin A, Bergström R, et al. Sternal wound complications incidence, microbiology and risk factors. Eur J Cardiothorac Surg. 1997; 11:1146-53.

4. El Oakley RM, Wright JE. Post-operative mediastinitis: classification and management. Ann Thorac Surg. 1996;61:1030-6.

5. Kirklin JW, Barratt-Boyes BG. Cardiac surgery. 2nd ed. New York: Churchill Livingstone; 1993. p. 225-6.

6. Bottio T, Vida VL, Gerosa G, et al. Double criss-cross sternal wiring and chest wound infections [letter]. Ann Thorac Surg. 2003. In press.

7. Robicsek F, Daugherty HK, Cook JW. The prevention and treatment of sternum separation following open-heart surgery. J Thorac Cardiovasc Surg. 1977;73:267-8.

8. Sutherland RD, Martinez HE, Guynes WA. A rapid, secure method of sternal closure. Cardiovascular diseases. Bull Texas Heart Inst. 1981; 8:54-5.

9. Nelson RM, Dries DJ. The economic implications of infections in cardiac surgery. Ann Thorac Surg. 1986;42:240-2.

10. Serry C, Bleck PC, Javid H, et al. Sternal wound complications: management and results. J Thorac Cardiovasc Surg. 1980;80:861-7.

11. Pairolero PC, Arnold PC, Harris JB. Long-term results of pectoralis major muscle transposition for infected sternotomy wounds. Ann Surg. 1991;213:583-90.

12. Losanoff JE, Jones JW, Richman BW. Primary closure of median sternotomy: techniques and principles. Cardiovasc Surg. 2002;10:102-10.

13. Losanoff JE, Richman BW, Jones JW. Disruption and infection of median sternotomy: a comprehensive review. Eur J Cardiothorac Surg. 2002;21:831-9.

14. Risnes I, Abdelnoor M, Baksaas ST, Lundblad R, Svennevig JL. Sternal wound infections in patients undergoing open heart surgery: randomized study comparing intracutaneous and transcutaneous suture techniques. Ann Thorac Surg. 2001;72:1587-91.

15. Hirose H, Takahashi A. Sternal suturing technique and chest wound complication [letter]. Ann Thorac Surg. 2002;74:634-5. 